\title{
Improving Reliability of cw Bar Laser Diodes by Novel Mounting
}

F.H. Mustafa

Received 25/04/2007
M.I. Azzawe

Physics Dept., College of Education

Mosul University

Accepted

07/06/2007

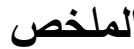

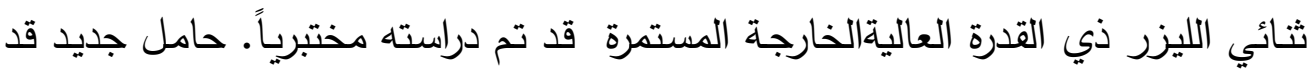

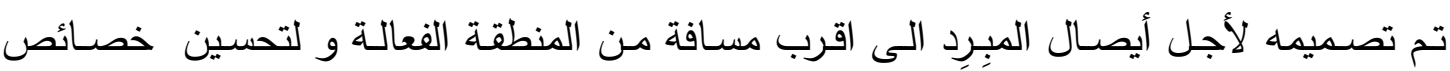

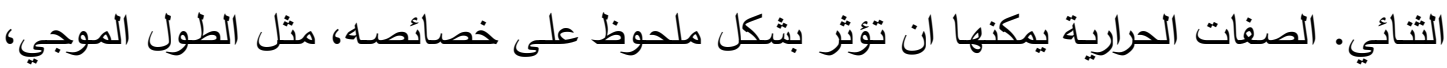

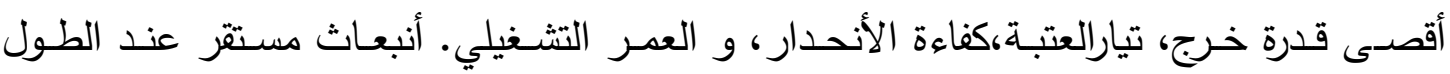

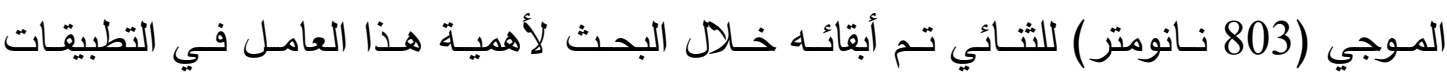
الدختلفة. كفاءة كمية خارجية عالية (1,66) و درجة الحرارة الخاصية و التي هي (106 دردية

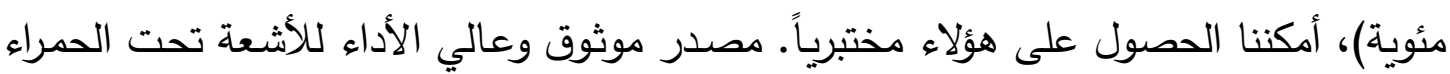

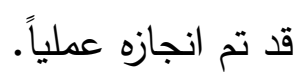

\section{Abstract}

High power bar laser diodes, with CW optical power output were studied experimentally. A novel mounting was designed to bring the coolant as close as possible to the laser bar in order to improve the bar laser diode characteristics. Thermal properties can influence significantly device characteristics, affecting wavelength, maximum output power, threshold current, slope efficiency and operating lifetime. Stable emission $(803 \mathrm{~nm})$ of the bar laser diodes was maintained during the investigation since it is very important for different kinds of applications. A high external quantum efficiency of (1.66) and a characteristic temperature of $(106 \mathrm{oC})$ were obtained in our experimental setup. A reliable and high performance IR bar laser diode source was achieved experimentally.

\section{INTRODUCTION}

High power laser diodes have become important scientific and commercial components. They are used in a wide variety of applications such as, IR spectroscopy [1], photonic industry [2], optical pumping to the Nd:YAG laser [3-6], photodynamic therapy [7], and space applications [8]. These devices are well suited for such applications due to their compactness, low cost, and excellent electrical to optical efficiency. Moreover, the use of these high power laser diodes has limited because of the low spatial and spectral stability performance [9], and the self-focusing effect due to the local heating of the active region 


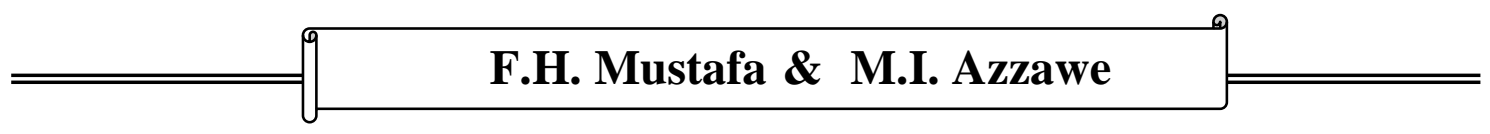

[10] . For optical pumping to the Nd:YAG laser requires a narrow linewidth in the near IR regime of $800 \mathrm{~nm}$ to $980 \mathrm{~nm}$ [11].

We report here on the commercial non-coated AR (anti-reflection) bar laser diodes (BLD's) with reduced linewidth, increased spatial brightness, low thermal resistance, and high external efficiency. This BLD can deliver up to $(24 \mathrm{~W})$ continuously. Low thermal resistance was achieved in our setup by minimizing the intra-package and package to heat sink interface which will enable the device to work with high power and external efficiency. On the other hand, low thermal resistance enable the BLD to be operated $\mathrm{CW}$ without sacrificing operating lifetime in addition to the superior performance. Narrow linewidth and stable wavelength emission were maintained during the operation of the BLD by the influence of high accurate current driving circuitry and temperature controller. These requirements are the conditions for good matching to solid-state gain media pumping requirements. There are several factors have to be considered for designing the BLD mounting. First, the mount must provide electrical and optical characterization capabilities, currentvoltage, current-power, and spectral \& spatial measurements. The mount of the BLD has the ability to control the temperature of the active region within the required stability with both the thermo-electric cooler (TEC) and the liquid nitrogen (the cryostat). These design aspects are discussed in Section II, the experimental part. In Section III, we present the results of our measurements on the BLD to extract the predicted high performance with the proposed technique. Finally, we will present the main concluded results of the investigation in Section IV.

\section{II.EXPERIMENTAL}

The BLD's under investigation has an output power of $(24 \mathrm{~W})$ and a threshold current of $(7.4 \mathrm{~A})$ at a temperature $(25 \mathrm{oC})$. The emission wavelength is in the IR region. Fig.(1) shows an illustration of the BLD used in the study, and a photo of the BLD under test. 

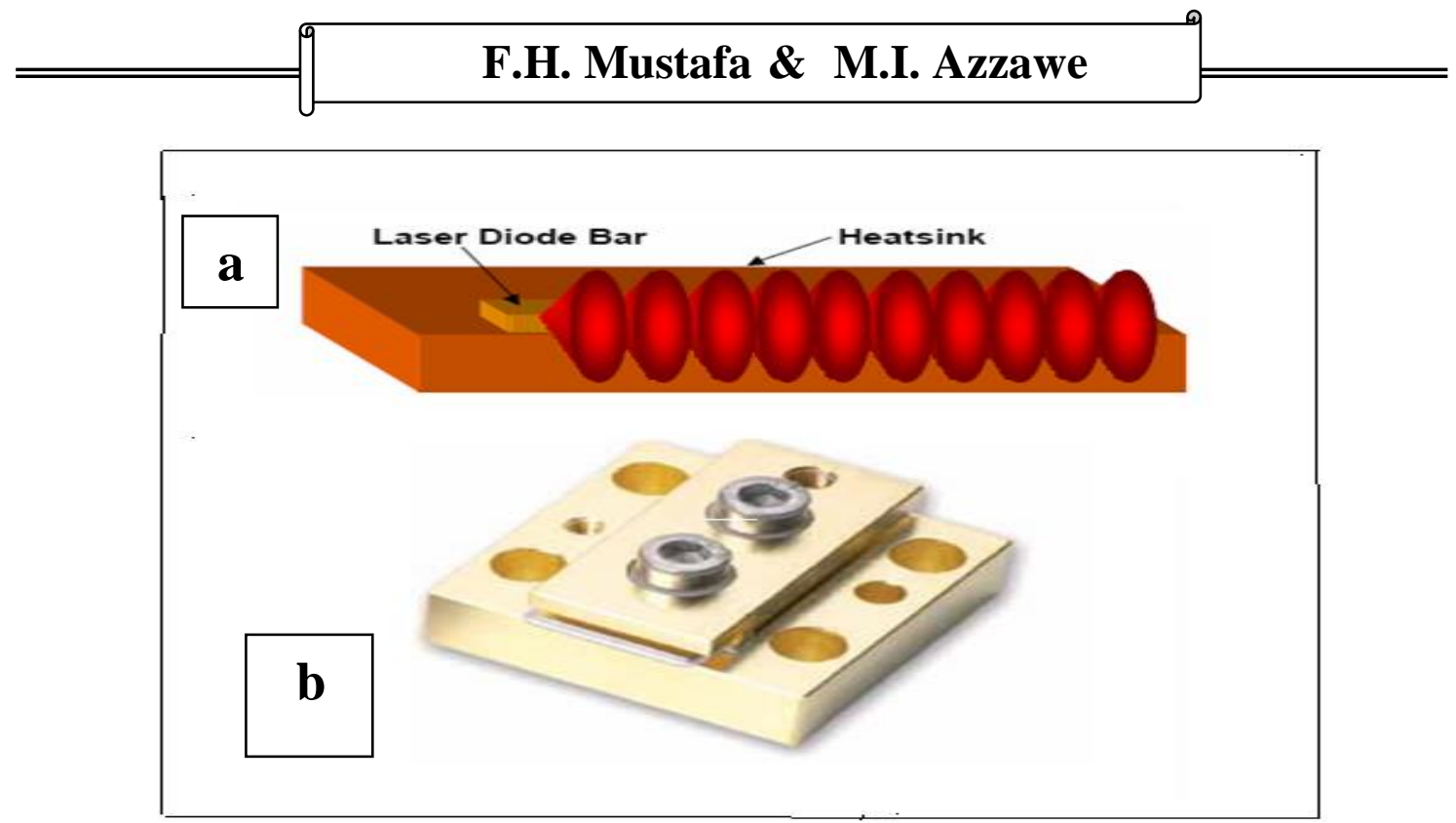

\section{Fig.(1): Bar laser diode [12]. a- is the simulation of the BLD emission b- is the photo of BLD used in the study.}

The BLD mount designed for the purpose of holding the laser bar and to perform the electrical and optical measurements is shown in Fig.(2). Most of the apparatus had been described in details elsewhere [12]. Keeping in mind that the main obstacle to operate the BLD in the $\mathrm{CW}$ mode is the heat delivered by the device. BLD was mounted on a copper block with p-side down to provide maximum extraction of heat energy from the active region and hence to make the coolant in contact with p potential. The BLD has to be conduction (passively) cooled in order to deliver the high power. The purpose of the submount (Cu-block) is to bring the coolant (TEC plus the liquid nitrogen) as close as possible to the actual heat generator (active region) and therefore higher power output. To maintain the maximum contact between BLD and the $\mathrm{Cu}$ block, the surface has to be very smooth (it was carried out with very fine machinery). Also, a thin film of Zinc oxide was applied between the two surfaces. To avoid any oxidation of the Cu-block, a thin layer of Nickel was deposited by electrochemical deposition. Cu-block would be considered as a heat sink and, moreover, as a metal contact to the BLD down to earthing.

Next to the Cu-block, a heat sink was placed underneath. Heat sinks come in many shapes and sizes. Typically one thinks of a finned $\mathrm{Cu}$ block which loses heat to its surrounding environment "efficiently" due to predominantly convective losses from its large surface area. By 'efficiently', we mean that the heat sink can be only slightly hotter than the surrounding environment while losing a lot of heat due to this temperature differential [12]. A big hole was made close to the outer surface of the heat sink for cryogenic cooling of the heat sink. This heat 


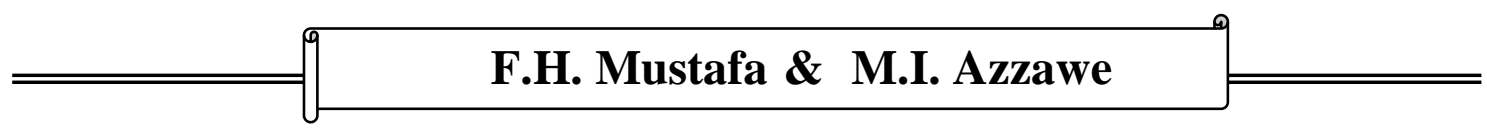

sink dissipates the excess heat from the bottom of TEC. To perform a better thermal conductivity the contact surface between the $\mathrm{Cu}$ - block, TEC, and Heat sink was filled with Zinc oxide paste.

The cryostat was a balloon shape of one liter capacity. A copper thin bar is bent into (L) letter shape. The longest arm $(10 \mathrm{~cm})$ was sunk in the liquid Nitrogen in the Cryostat, and the shorter arm $(7 \mathrm{~cm})$ was outside and in direct contact with the heat sink. The whole system is isolated from the environment with isolating foam. A Copper -Constantan thermocouple was used to measure the temperature of bar laser diode (BLD). The junction was placed in the $\mathrm{Cu}$ - block in the vicinity of BLD. A digital thermometer was used in conjunction with the thermocouple. This system can be efficiently cool the BLD below its operating temperature $( \pm 40 \mathrm{oC})$.

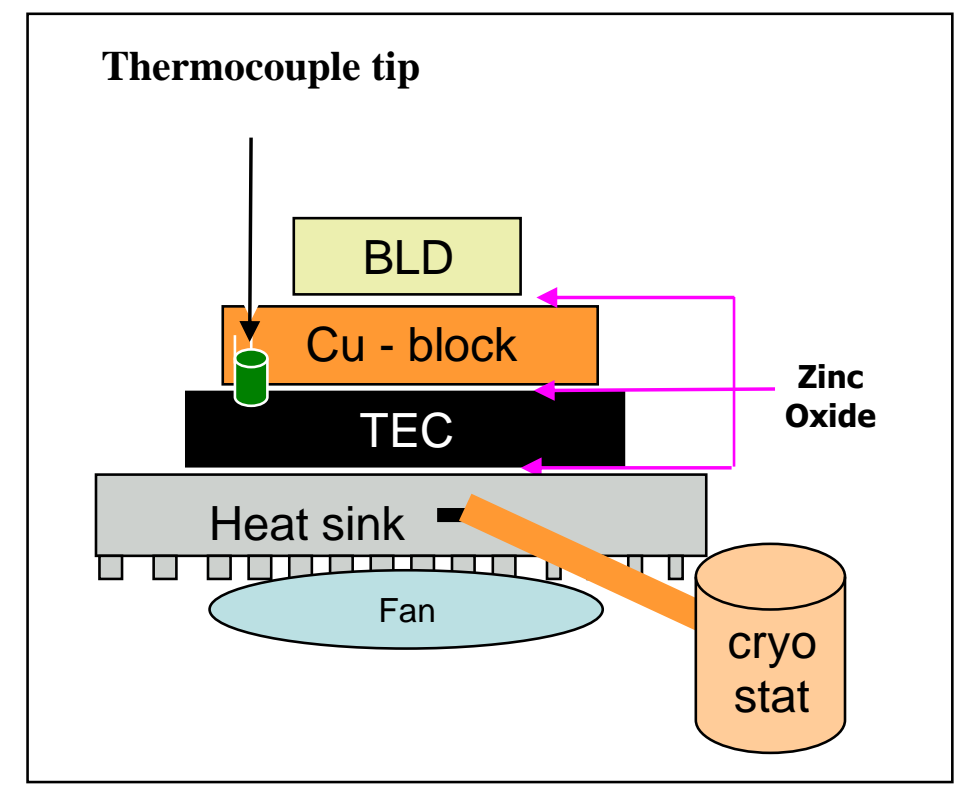

Fig.(2): Block diagram of the BLD mounting.

Fig.(3) illustrates the change of the operating temperature of the $\mathrm{Cu}$ block with time as $(\Delta \mathrm{T} / \Delta \mathrm{t})$, and it was found to be equal to $(4.9 \times 10-4$, , $22 \times 10-4,55 \times 10-4,73 \times 10-4$ and $\left.57 \times 10-4{ }^{\circ} \mathrm{C} / \mathrm{min}\right)$ at temperatures $(12.5$, $19,22,26,32$ oC)respectively. The graph shows high stability near ambient temperature more than below or above ambient temperature $(23 \mathrm{oC})$.

When the driving current of the bar laser diode is greater than the allowable limit, even for a fraction of a second, the BLD will be damaged. The extend of damage depends on the sensitivity at the particular diode. The sensitivity of the BLD to over current is due to fast response of the laser output to the driver current variation. Hence we have built a very reliable 

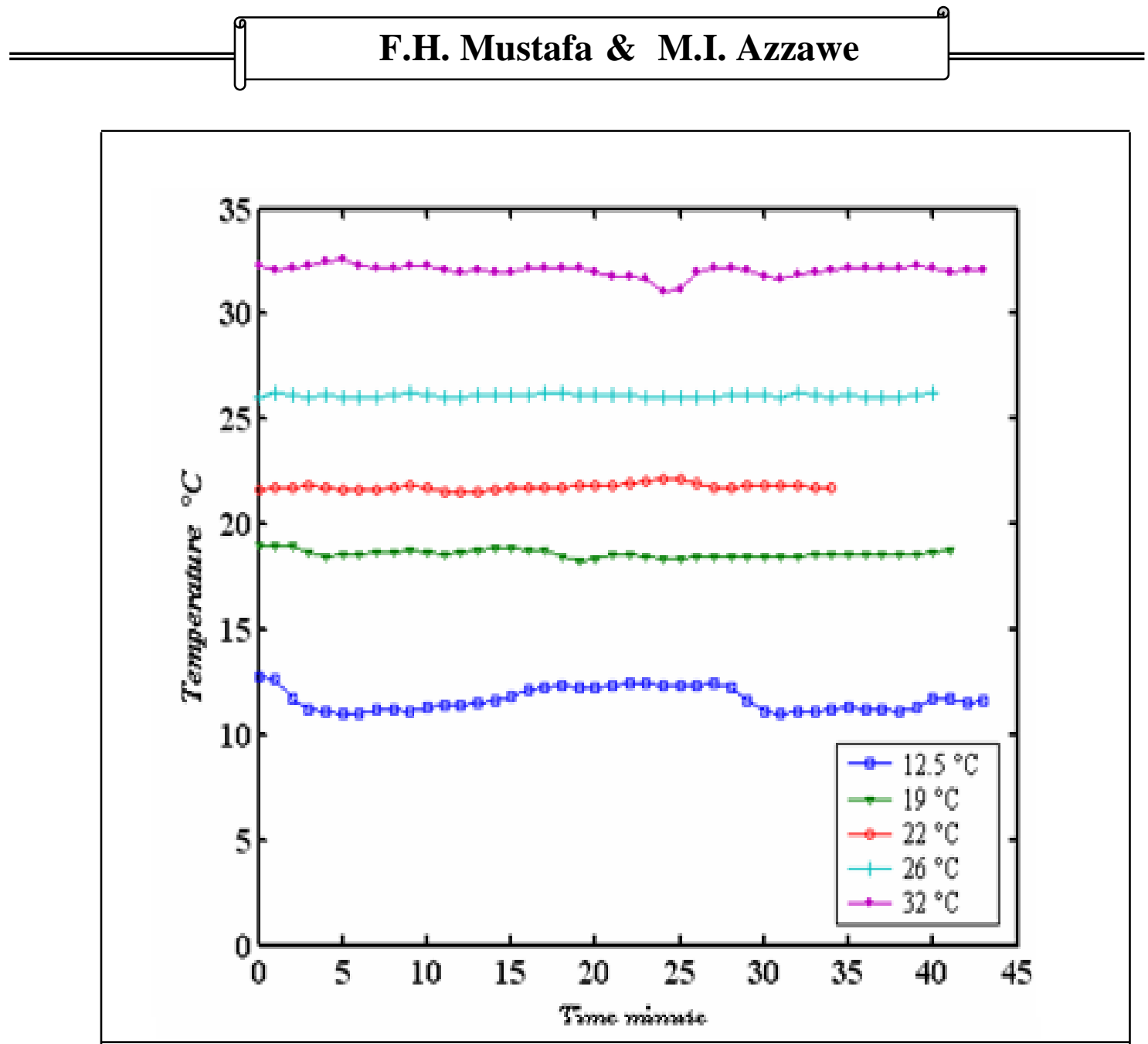

Fig.(3) show s the variation of Cu-block temper ature with time, the stability diagram at differ ent temper atures.

and accurate current controller for driving the BLD [12]. The driving circuitry of the laser diode is very essential in order to stabilize the power output and emission wavelength.

The experimental setup used for the current-power and current- voltage measurements is shown in Fig.(4). As can be seen from the schematic diagram, a neutral density was inserted between the BLD and the photodiode. This neutral density was essential in the experimental procedure in order to protect the photodiode from the high power emission from the BLD and to work beyond the saturation limit of the photodiode. The neutral density must attenuate without affecting the emission wavelength. We have tested many substances until we reached the best material for the BLD emission wavelength. Fig.(5) shows the IR transmission and absorbance curves of the filter we obtained. The measurements were carried out by the IR spectrometer (SHINADZU). It is obvious from the curves that suitability 


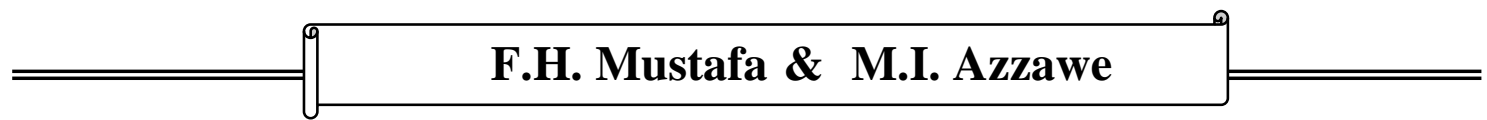

of the filter to the required attenuation of the BLD power emission and no influence on the emission wavelength.

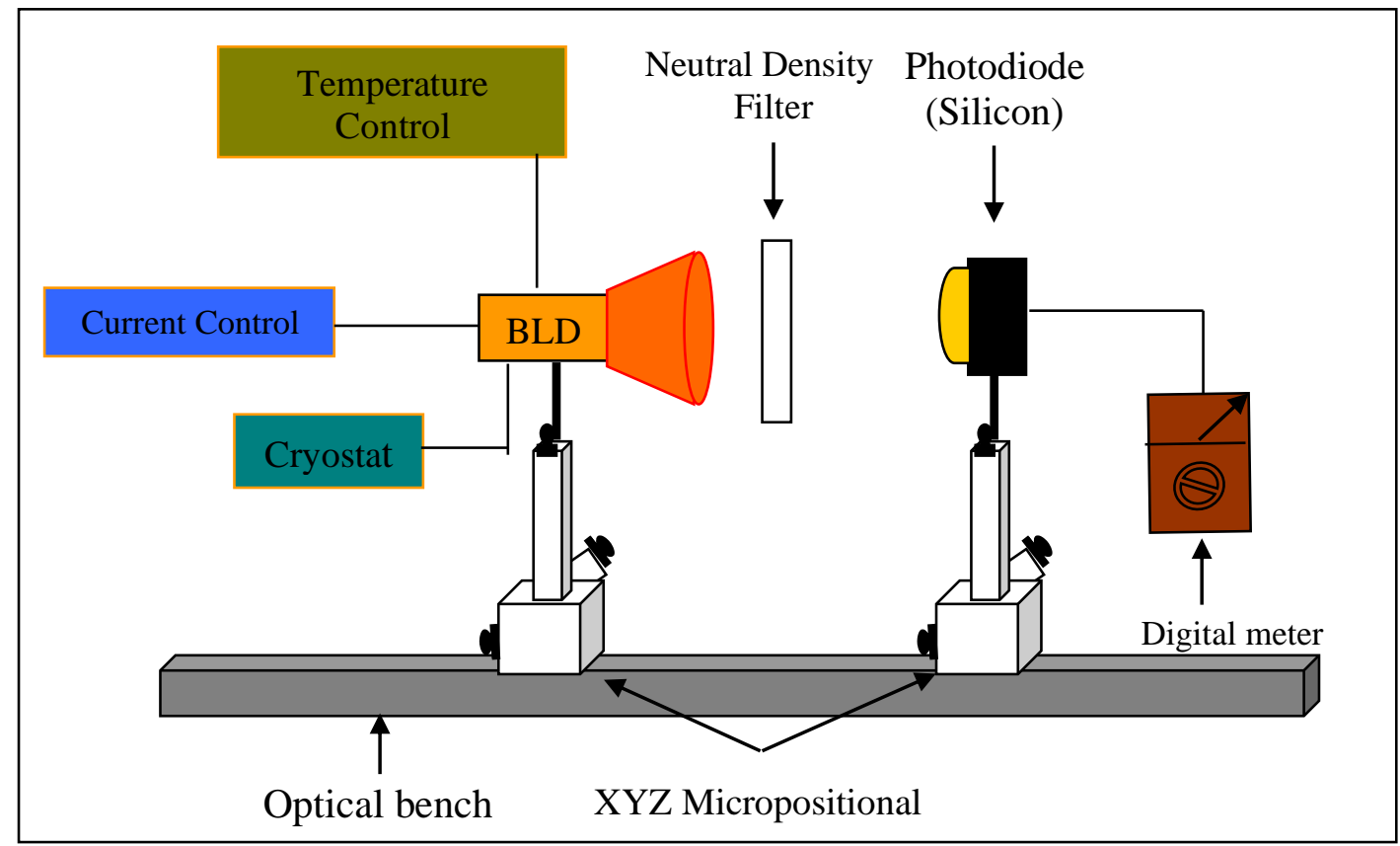

Fig.(4):Schematic diagram for characterizing (current-power and current-voltage) of the BLD.

BLD mount, Fig.(2), was coupled to a 3D-micropositional translator in order to get a fine adjustment of the optical alignment of all components. The micropositional was then fixed to the optical bench. The alignment was carried out with the aid of the photodiode and a digital meter for maximum reading when all aligned with the same optical axis.

The photodiode used in our study was a Si-photodiode (FDS100Thorlab) having a good response from visible to IR (500-1000 nm) an ideal for measuring optical power within that wavelength range. The detector is a high-speed photodiode, with a large active area of $(13 \mathrm{~mm} 2)$. This type of photodiode has a fast rise and fall times (10 ns) with a bias of (20V). A power meter with this detector was established for direct measuring of power output in Watt from converting the generated photocurrent across a precision resistance. 


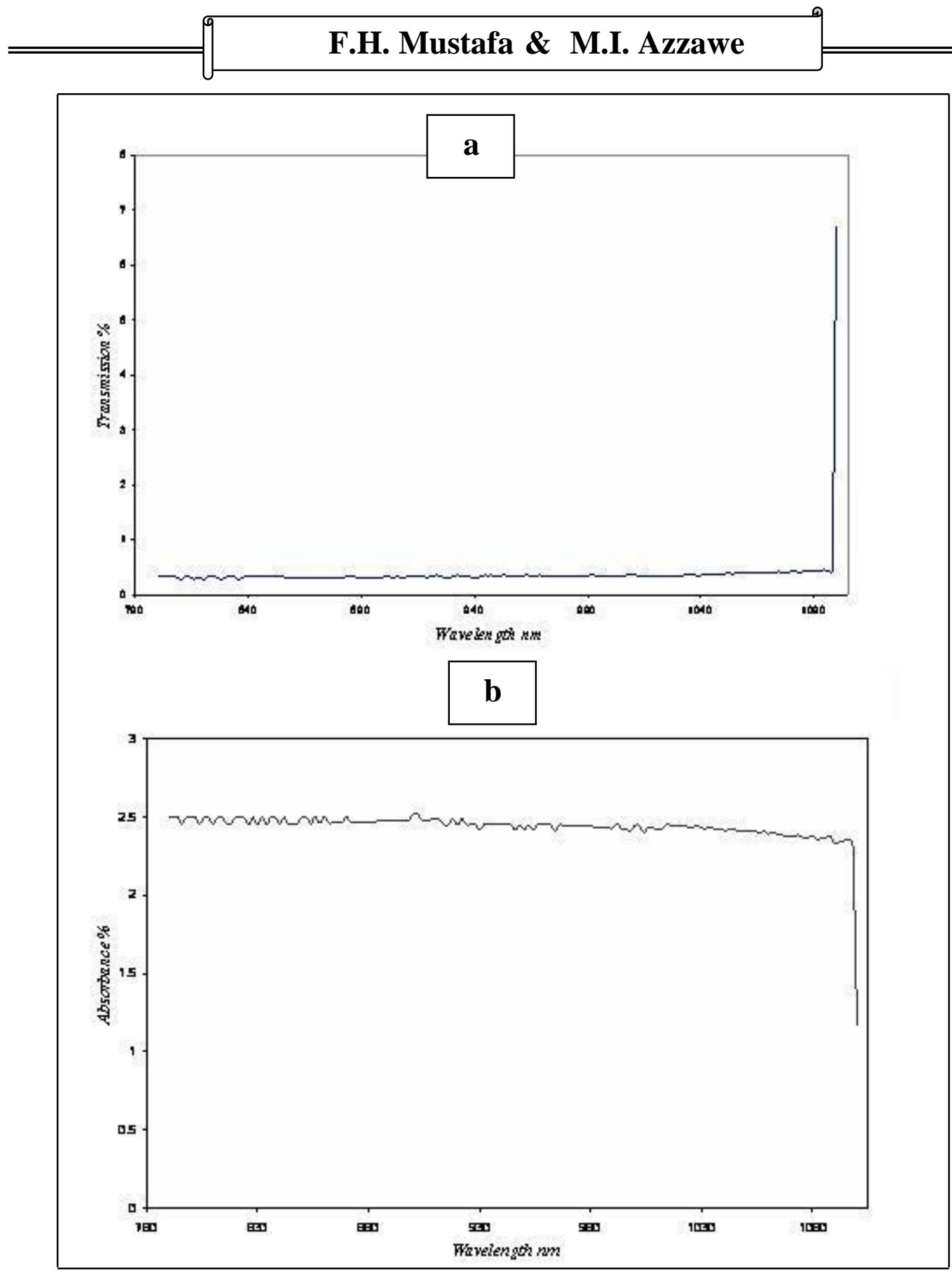

Fig.(5): Neutral density filter IR characteristic curves for: a-transmittance b-absorbance

For spectral measurements, an experimental apparatus was established as given by the schematic diagram of Fig.(6). 

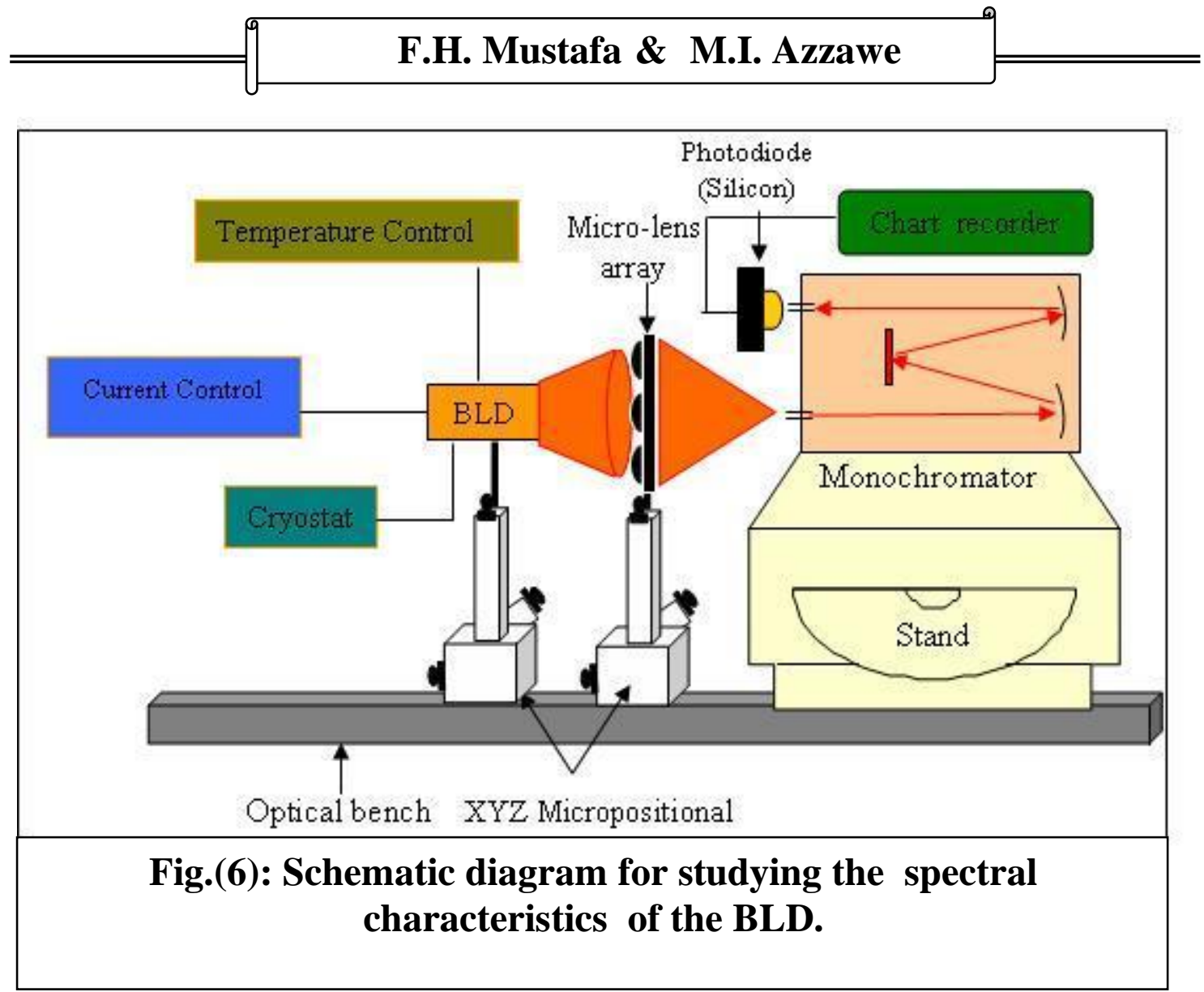

The BLD output (above threshold current) was directed to the input of a monochromator (MP-1018B) and was adjusted with an entrance slit of $(30 \mu \mathrm{m})$ and speed scan rate of $(2 \mathrm{~nm} / \mathrm{min})$. The output of the monochromator was received by a photodiode (FDS100) which was placed in front of the exit slit. The photodiode output was connected to a chart recorder via a preamplifier of $(2 \mathrm{~V})$ full scale and $(2 \mathrm{~cm} / \mathrm{min})$ paper advance rate. Records of the emission spectra over a range $( \pm 4 \mathrm{~nm})$ from the nominal emission wavelength were obtained. Before performing the experiment, the monochromator was calibrated with a He-Ne laser.

\section{RESULTS \& DISCUSSION}

Results of this investigation are mainly concerned with the optimum operating conditions of the BLD for obtaining maximum power output, high efficiency, narrow linewidth, and stable emission.

Fig.(7) shows the current-power characteristics at different temperatures. The principle parameters that can be deduced from the curves are the; threshold current, and external quantum efficiency as a temperature dependence. The external quantum efficiency $\left(\eta_{\text {ext }}\right)$ was obtained from the slope efficiency as [12]:

$$
\eta_{\text {ext }}=\eta_{i} \frac{2 \mathrm{q}}{h v} \times \frac{\Delta \mathrm{P}_{\text {out }}}{\Delta \mathrm{I}}
$$




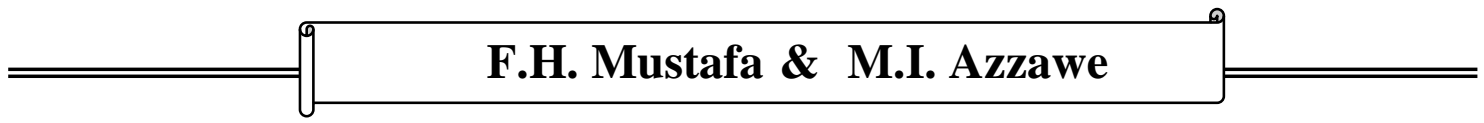

With $\eta \mathrm{i}$ is the internal quantum efficiency, $\mathrm{q}$ is the electronic charge, $\mathrm{h}$ is the Planck's constant, $v$ is the frequency and $\frac{\Delta \mathrm{P}_{\text {out }}}{\Delta \mathrm{I}}$ is the slope efficiency of the BLD.

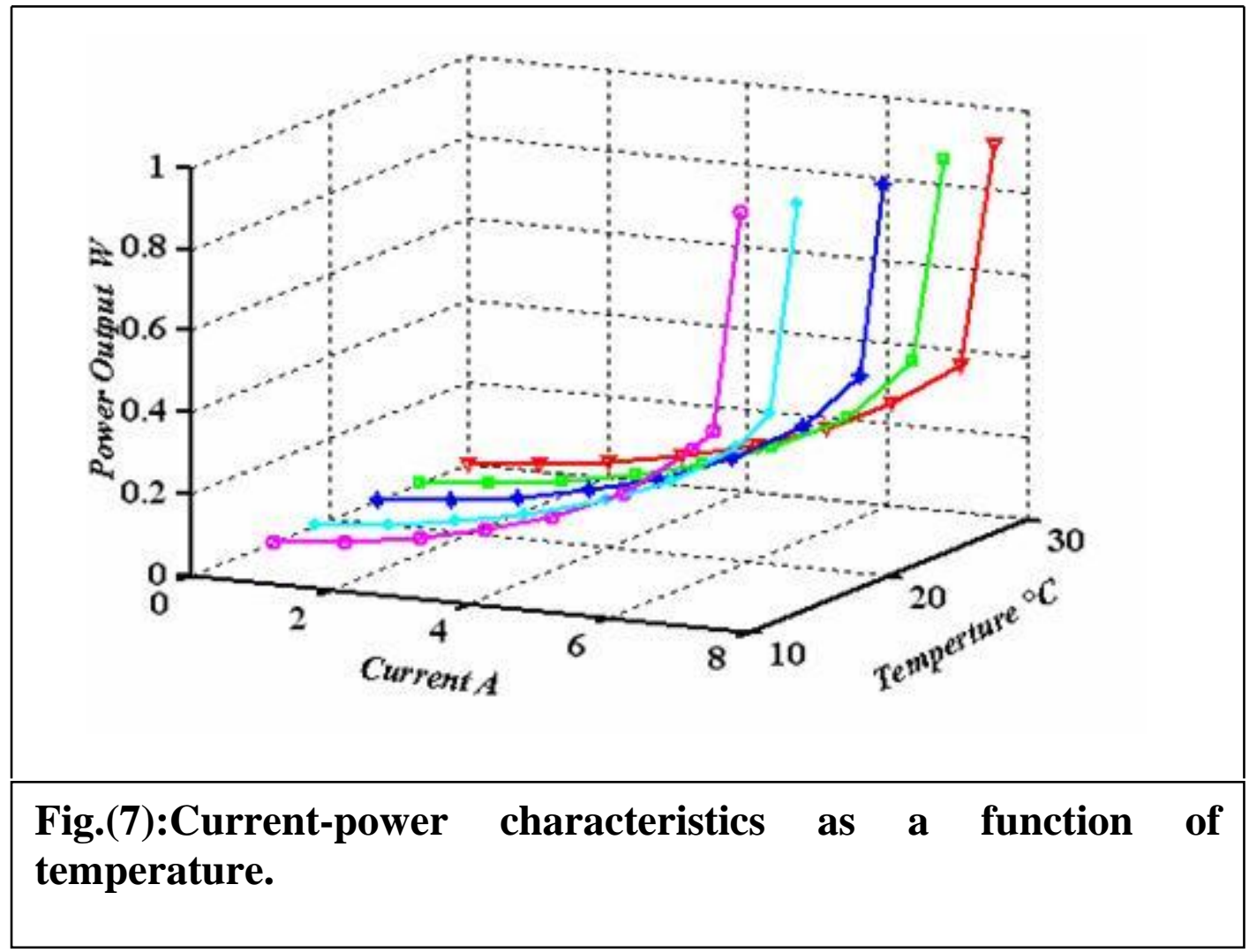

In most applications, the ability of the BLD to perform well at elevated temperatures is of great interest. This is especially of concern in the case of high power laser diodes where the amount of heat generated causes the device temperature to rise significantly. As a result, it is of outmost importance for the semiconductor crystal to be robust enough so as not to degrade due to device operation at high temperatures. The threshold increase with temperature follows the exponential relation as given by [13]:

$$
\text { Ith(T) } \alpha \exp (\mathrm{T} / \mathrm{To})
$$

Where To is called the characteristic temperature of the device.

Experimentally, we found the relation between the threshold current and the temperature as in the following equation:

$$
\operatorname{Ith}(\mathrm{T})=\text { Itho }[\exp (-\mathrm{u} 1 \mathrm{~T} 2) \times \exp (\mathrm{u} 2 \mathrm{~T})]
$$

With $\mathrm{u} 1=23 \times 10-5(1 / \mathrm{oC})$, and $\mathrm{u} 2=19 \times 10-3(1 / \mathrm{oC})$, and Itho=1.6 A. 


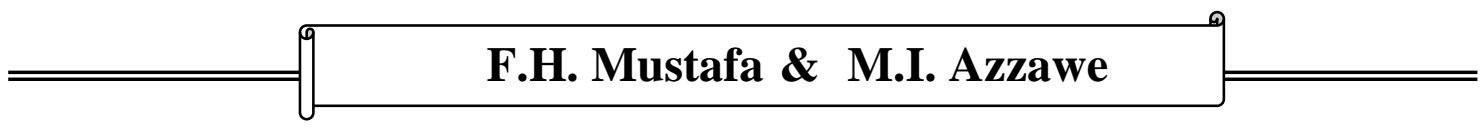

At high temperature, the first term of the above equation was more effective on the laser dynamics. Break in the characteristics was because of the factor $\mathrm{u} 1$ that plays an important role in high temperature operation. This was due to carrier leakage, free carrier losses, and nonradiative process. The measured temperature dependence of threshold current at low temperature was determined by the radiative recombination and $(\mathrm{u} 2=1 / \mathrm{To})$ is the inverse characteristic temperature of the device. The characteristic temperature of the device BLD was determined, $\left(\mathrm{T} 0=106^{\circ} \mathrm{C}\right)$. It represents temperature sensitivity of the device, and high value of T0 implies that the threshold current of the device increases less rapidly with increasing temperature.

Current-voltage (I-V) characteristics determine the device quality. By measuring the BLD (I-V) characteristics we could determine the barrier voltage and the series resistance. Under forward bias condition, the current injection was obtained after a turn-on voltage, and for bigger voltage values, a linear dependence between the current and voltage values was observed. The I-V curve of the BLD under test had the properties of barrier voltage, saturation current, and series resistance. Fig.(8) represents the I-V relationship as a function of temperature.

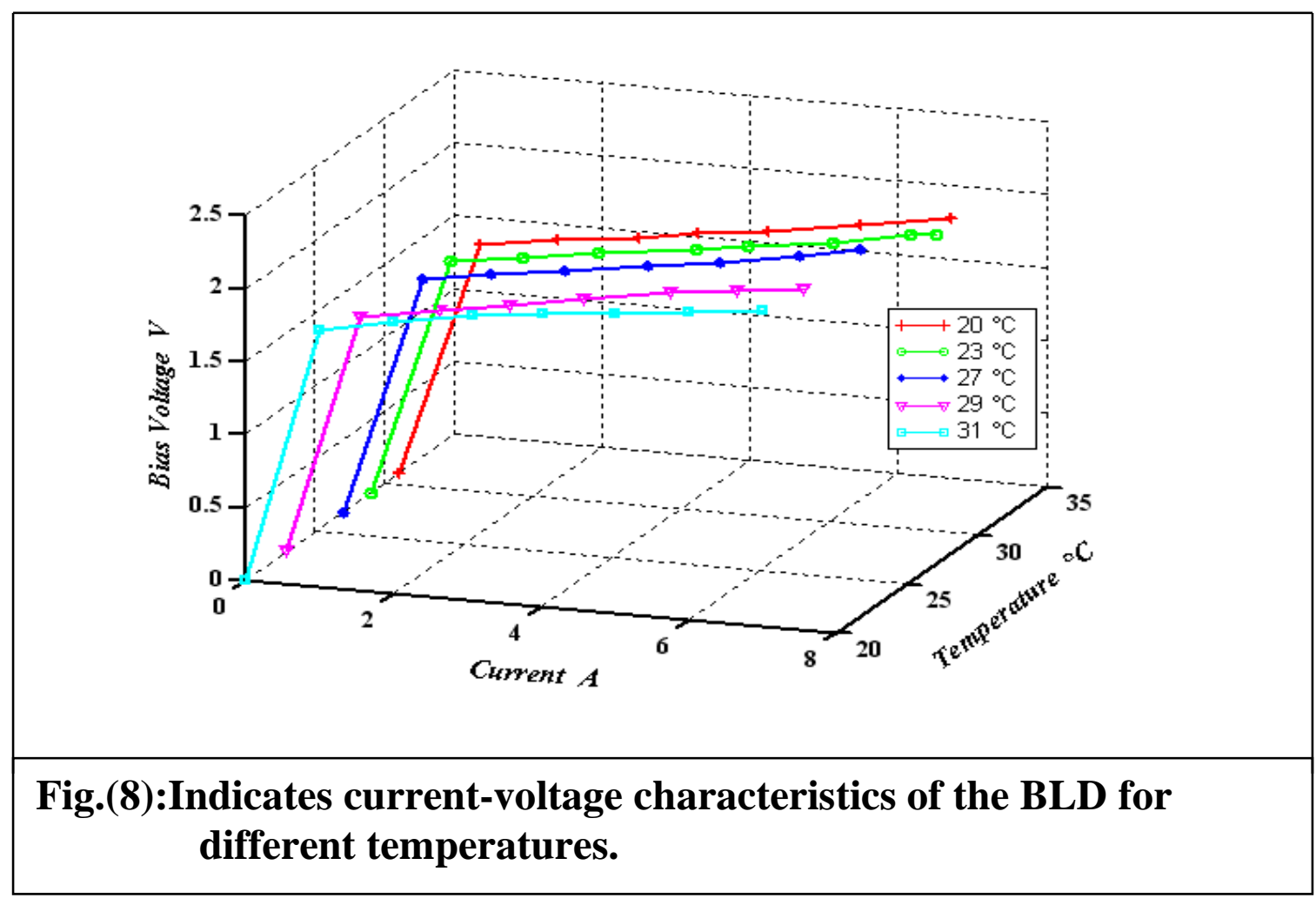


The external quantum efficiency of BLD was also temperature dependent. This dependence was not linear, and the best fitting of the curve was cubic as in the following equation:

$$
\ln (\eta \operatorname{ext})=-22 \times 10-5 \mathrm{~T} 3+13 \times 10-3 \mathrm{~T} 2-0.2 \times \mathrm{T}+2.2
$$

By taking exponential of both sides Eq.(5) we get:

$$
\eta \operatorname{ext}=\exp (-\mathrm{f} 1 \mathrm{~T} 3+\mathrm{f} 2 \mathrm{~T} 2-\mathrm{f} 3 \mathrm{~T}+\mathrm{f} 4)
$$

or as:

$$
\begin{gathered}
\eta_{\text {ext }}=\frac{\exp \left(\mathrm{f}_{4}\right) \cdot \exp \left(\mathrm{f}_{2} \mathrm{~T}^{2}\right)}{\exp \left(\mathrm{f}_{1} \mathrm{~T}^{3}\right) \cdot \exp \left(\mathrm{f}_{3} \mathrm{~T}\right)} \\
\eta_{\text {ext }}=\frac{\eta_{\text {bulk }} \times \eta_{\text {coupling }}}{\eta_{\text {carrier }} \times \eta_{\text {int ernal }}}
\end{gathered}
$$

Where $\eta$ carrier is the carrier efficiency, $\eta$ bulk is the bulk

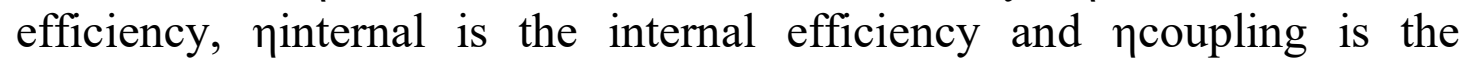
coupling efficiency. The above equation indicates that each term of the external quantum efficiency is a function of temperature. The carrier efficiency decreased with temperature as a relation ( $\eta$ carrier $\alpha$ T3), because the number of carrier injected to the active region may be reduced with temperature due to the carrier losses (leakage current), so that a smaller fraction of number carriers pass through the device. The external quantum efficiency also increased with bulk efficiency ( $\eta$ bulk), because the number of photons available in the lasing increase due to increased number of photons in the active region. The third term was decreased with temperature as a relation ( $\eta$ internal $\alpha$ T), known as internal quantum efficiency which was always smaller than one, because a smaller fraction of carriers (electron and holes) does not recombine in the active region due to heated, then the nonradiative radiation occurs due to (Auger recombination) [13]. The coupling efficiency is the most important part of the external quantum efficiency, the $\eta_{\text {ext }}$ was linearly increased with $\eta$ coupling, because the number of photons generated in the active region was a function of photons are backed from mirrors, so that a larger fraction of number photons are escaped then the coupling efficiency increases. The characteristic values of BLD and for better understanding the temperature dependence of the BLD parameters are presented in Table (1).

The power spectrum of a semiconductor laser is an important device characteristic since in many applications the spectral control of the laser output is required, such as in this study for pumping Nd:YAG laser in 


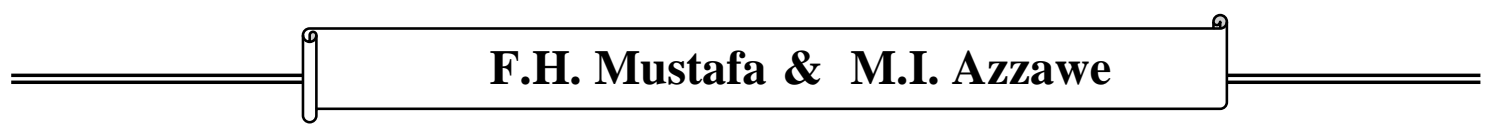

order to maintain stable output. Fig. (9) shows the optical power spectra of the BLD as a function of injection current. The spectra were below the threshold current such as (2A, 4A, 5A and 6A), i.e., the outputs light emitted were spontaneous emission. The BLD acted as an LED with a large spectral width. As the threshold was approached (around 6A), the spectrum narrowed considerably and several peaks appeared and got maximum light intensity when compared to the other peak curve like (2A, $4 \mathrm{~A}$ and $5 \mathrm{~A})$.

Table(1): Represents the experimental results for optical and electrical BLD parameters as a function of temperature.

\begin{tabular}{|c|c|c|c|c|c|c|}
\hline $\begin{array}{c}\text { Parameter } \\
\text { description }\end{array}$ & Temperature $\left({ }^{\circ} \mathrm{C}\right)$ & 16 & 19 & 23.5 & 26.5 & 30 \\
\hline Threshold & $\mathrm{I}_{\text {th }}(\mathrm{A})$ & 6 & 6.2 & 6.41 & 6.627 & 6.701 \\
\hline $\begin{array}{c}\text { Saturation } \\
\text { current }\end{array}$ & $\mathrm{Is}(\mathrm{pA})$ & 185 & 215 & 278 & 320 & 430 \\
\hline $\begin{array}{c}\text { Slope } \\
\text { efficiency }\end{array}$ & $\mathrm{S} . \mathrm{E}(\mathrm{W} / \mathrm{A})$ & 1.366 & 1.3024 & 1.277 & 1.1033 & 0.9295 \\
\hline $\begin{array}{c}\text { Potential } \\
\text { barrier }\end{array}$ & $\mathrm{V}_{\mathrm{b}}(\mathrm{V})$ & 1.61 & 1.5835 & 1.574 & 1.5612 & 1.542 \\
\hline Energy gap & $\mathrm{E}_{\mathrm{g}}(\mathrm{eV})$ & 1.551 & 1.546 & 1.544 & 1.541 & 1.540 \\
\hline $\begin{array}{c}\text { Series } \\
\text { resistance }\end{array}$ & $\mathrm{R}_{\mathrm{s}}(\mathrm{m} \Omega)$ & 78.5 & 76.5 & 74.3 & 73.5 & 69.5 \\
\hline $\begin{array}{c}\text { Ext. } \\
\text { quantum } \\
\text { efficiency }\end{array}$ & $\eta_{\mathrm{ext}}$ & 1.77 & 1.69 & 1.66 & 1.43 & 1.2 \\
\hline wavelength & $\lambda(\mathrm{nm})$ & 801.31 & 803.08 & 804.97 & 806.65 & 807.17 \\
\hline
\end{tabular}

Two things are worth noticing in the spectrum change, first it can be seen that several sub-peaks in the spectrum observed at (6A), spacing apart, which the mode are spacing apart. Only one of these peak modes became the dominant mode as the current was increased. If the diode lasers are driven by continues currents, the produced heat due to this current may easily damage the sample by changing the electronic structure.

When the BLD operated above threshold region, the multilongitudinal modes closest to the gain peak increased in power. The lasing spectra of a BLD are shown in Fig.( 10). Multi-longitudinal modes and high transverse modes oscillation were obtained for injection current larger than threshold current. The increase in driving current will heat the laser active region, and hence the emission will be shifted to a longer wavelength. The wavelength of the BLD was determined by its structure and the bandgap of its active layer. The operating wavelength changed 


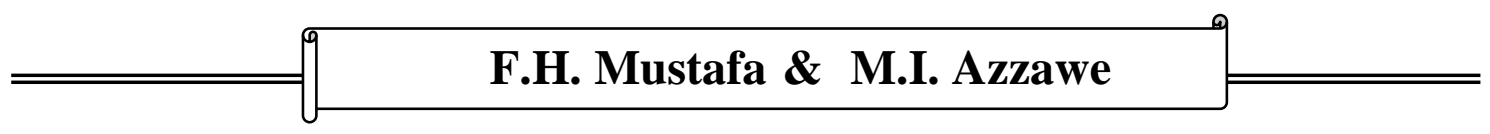

with temperature and drive current so the laser can be tuned over a limited range by controlling operating conditions.

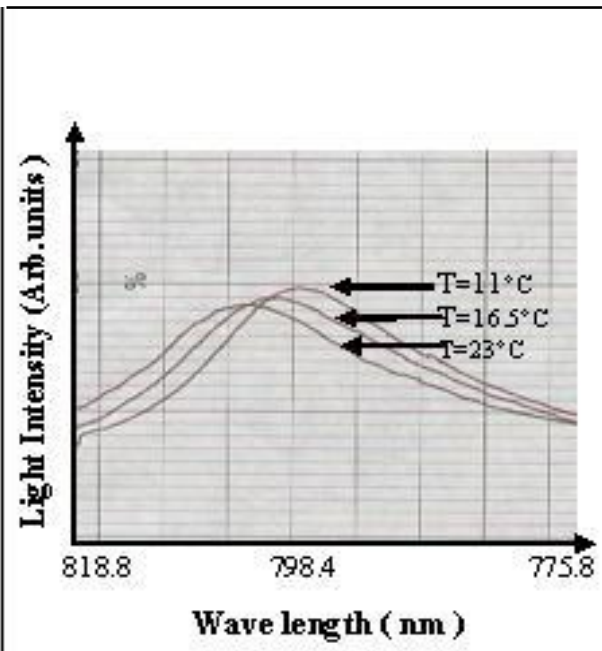

(a)

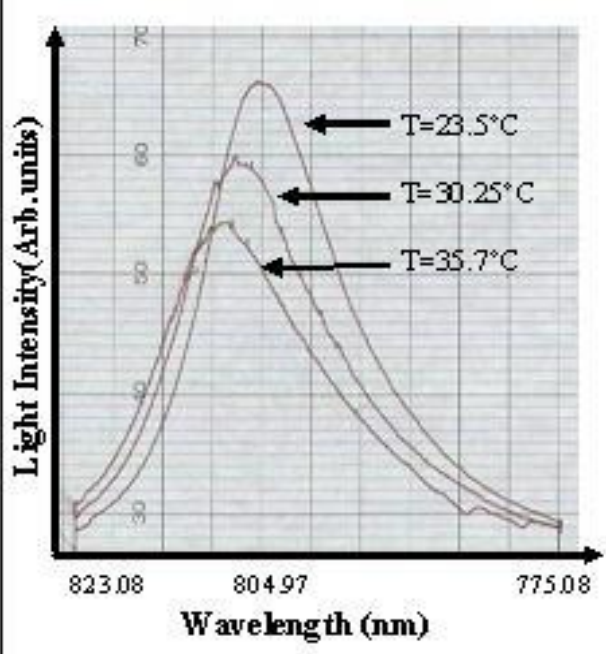

(c)

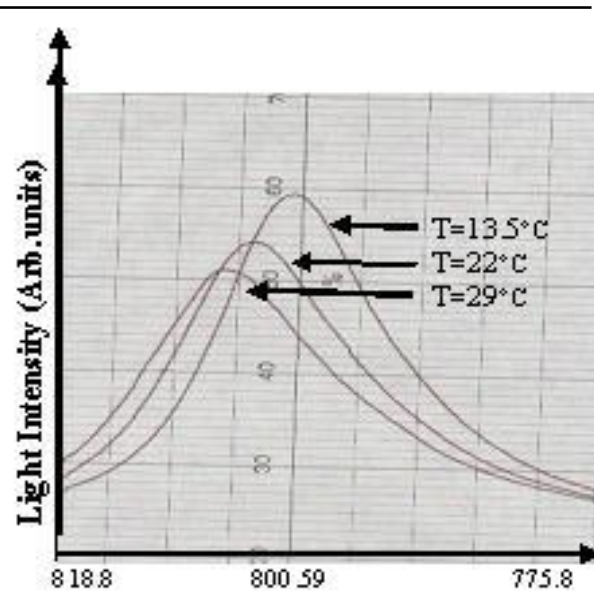

Wavelength (nm)

(b)

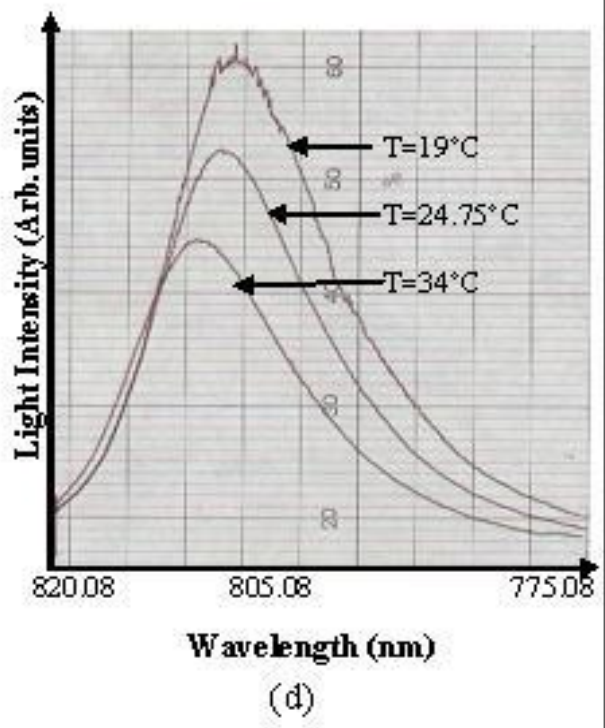

(d)

Fig.(9): The spontaneous emission spectra which were taken with different injection current:

(a) BLD spectra from $\left(11\right.$ to $\left.23^{\circ} \mathrm{C}\right)$ with current fixed at (2A).

(b) BLD spectra from $\left(13.5\right.$ to $\left.29^{\circ} \mathrm{C}\right)$ with current fixed at (4A).

(c ) BLD spectra from $\left(19\right.$ to $\left.34^{\circ} \mathrm{C}\right)$ with current fixed at (5A).

(d) BLD spectra from $\left(23.5\right.$ to $\left.35.7^{\circ} \mathrm{C}\right)$ with current fixed at $(6 \mathrm{~A})$.

The peak wavelength shift had occurred with the increase in injection current. The change in peak wavelength with current was about $(1.6 \mathrm{~nm} / \mathrm{A})$ at high current injection. Due to the high injection current, the temperature of the active medium will increase, giving rise to a peak wavelength shift to a higher wavelength. But, at low injection current the change in peak wavelength was about $(0.12 \mathrm{~nm} / \mathrm{A})$. 

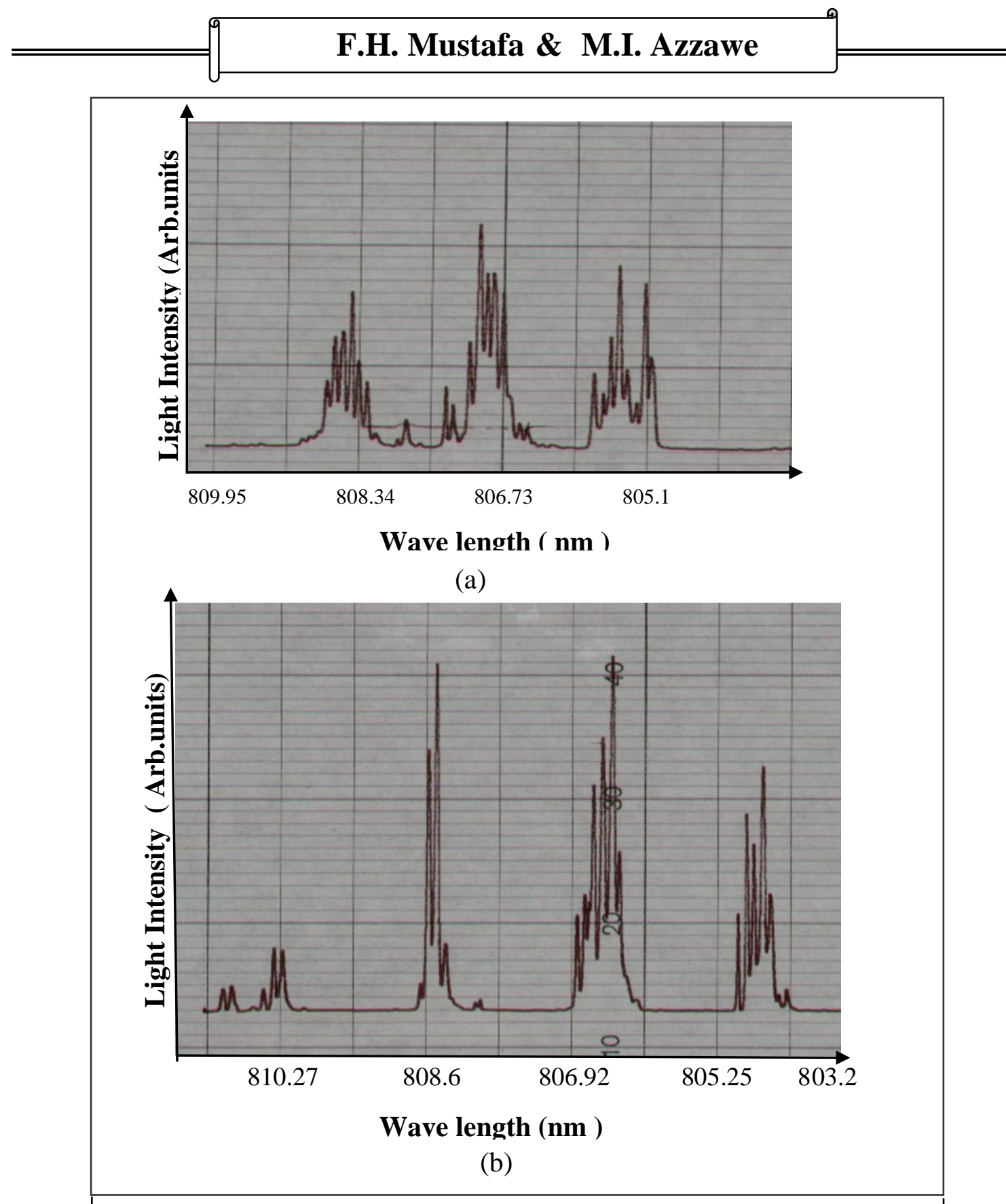

Fig.(11): BLD lasing spectra:

(a) At current $(7.8 \mathrm{~A})$ with operating temperature $\left(24^{\circ} \mathrm{C}\right)$. (b)At current $(8.4 \mathrm{~A})$ with operating temperature $\left(27^{\circ} \mathrm{C}\right)$.

The peak wavelength $\left(\lambda_{\mathrm{p}}\right)$ of the BLD is directly proportional to its operating temperature. There is a linear relationship between temperature and peak wavelength as shown in Fig.(11). When the peak wavelength shifted too far, the laser jumps to another mode. The reason for this shift in $\left(\lambda_{p}\right)$ was due to shrinkage in energy gap of active medium with temperature. 

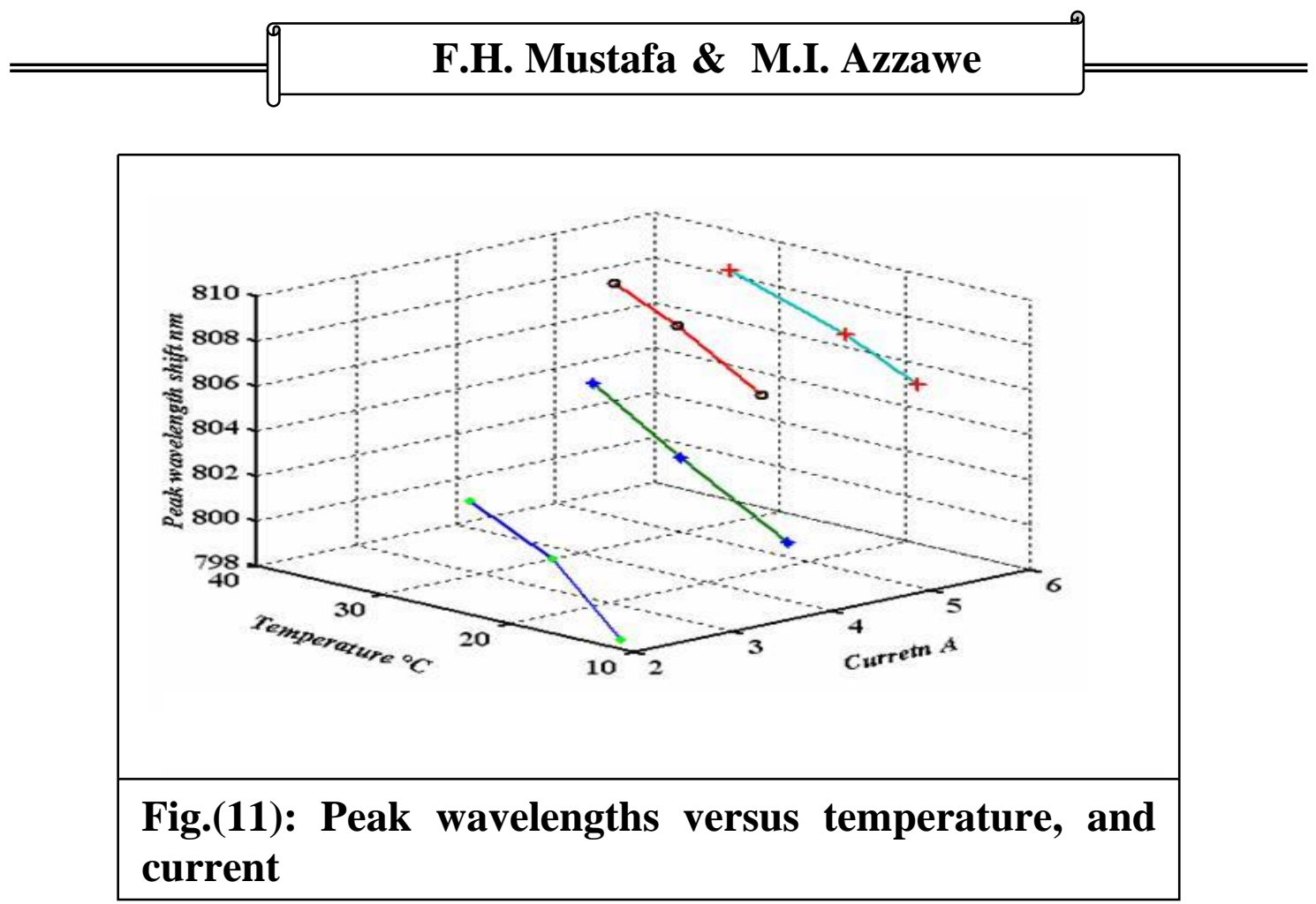

The spectral characteristics of the BLD was studied thoroughly when the full-width at half-maximum (FWHM) of the spectra were plotted as in Fig.(12). The spectral FWHM of the BLD was decreased with the increasing injection current. The FWHM was $(20 \mathrm{~nm}$ ) at low injection level (below threshold), at certain temperature, and dropped dramatically to $(2 \mathrm{~nm})$ at high power output (well above threshold).

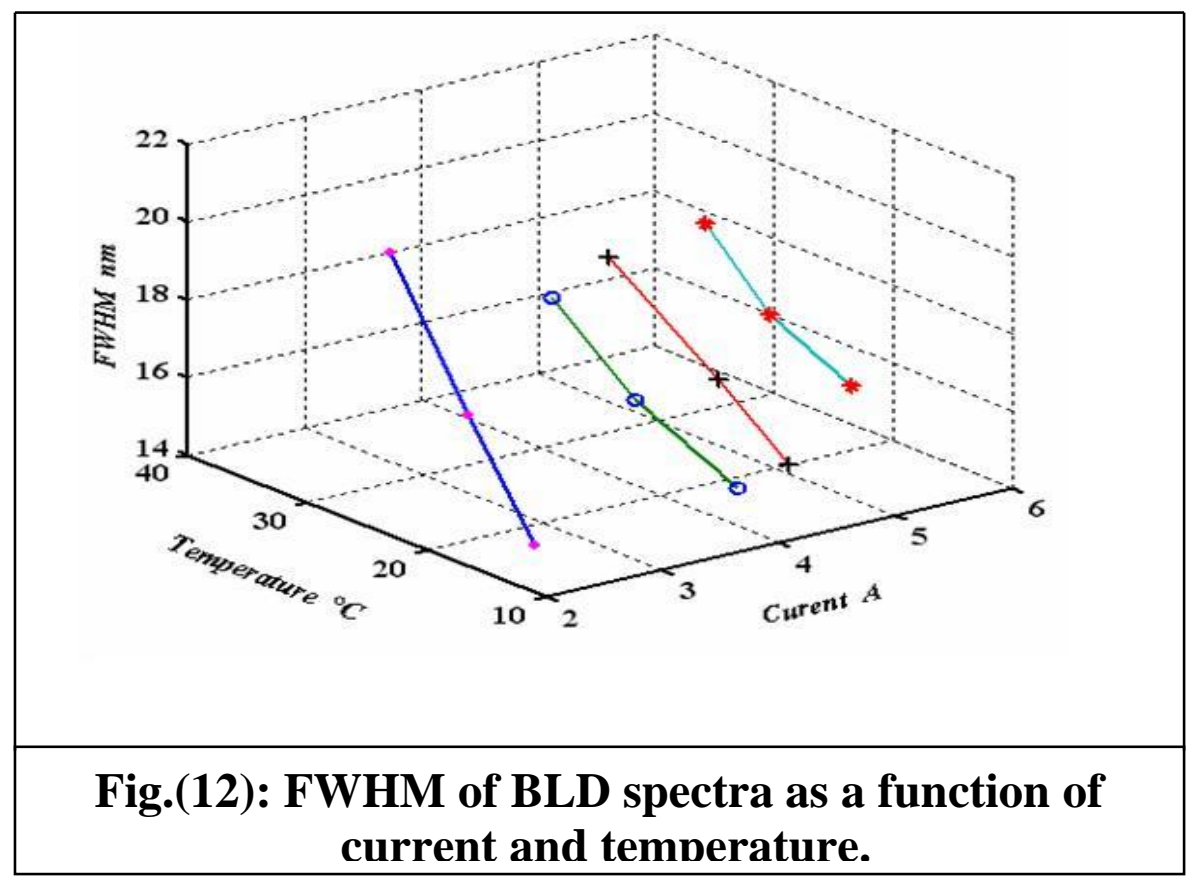

\section{CONCLUSIONS}

The bright future of BLD relies on its reliability and stable high power output for many replacements in the industrial use [14]. The exceptional combination of high power output at low beam parameter 
product $\mathrm{BPP}$ ( $\mathrm{BPP}=$ divergence angle $\mathrm{x}$ focal radius) [15], is the characteristic feature of any BLD, i.e., figure of merit. BLD mount was extremely the main objective of our study due to their influence on the operating characteristics. The active heat sink which we designed allows the coolant (liquid nitrogen) to come as close as few millimeters to the active region. This will reduce the difference in the thermal expansion coefficients of the BLD and the heat sink, otherwise a compressive or induced-stress will be occurred [16,17]. Numerical modeling of the overheating of high power laser bars has shown that mutual heating of the individual lasers in the bar and causes the heat spreaders [18]. We have been able to operate the BLD in the $\mathrm{CW}$ mode with high external quantum efficiency (1.66) at a temperature of $(23.50 \mathrm{C})$, which is better than reported in Ref.[7]. Emission stability was maintained during the operation of the BLD with an acceptable FWHM of the wavelength emission of $(<2 \mathrm{~nm})$. Moreover, we demonstrated that the BLD has a high value of To $(106 \mathrm{oC})$.

\section{REFERENCES}

1. Douberly, G.E., Merritt, J.M. and Miller, R.E., Phys. Chem. Chem. Phys. 7,463 (2005).

2. Wolff, D., Bonati, G., Henning, P., and Voelckel, H., Proc. SPIE 5711-02 (2005).

3. Coyle, D.B., Kay, R.B., Stysley, P.R., and Poulios, D., Appl. Opt. 43, 5236 (2004).

4. Gourevitch, A. et al., Appl. Phys. Lett. 83, 617 (2003).

5. Bass, M., Dong, J., IEEE J. of Quantum Electronics, 41, 183 (2005).

6. Boulon, G. et al., Opt. Materials 24,377 (2003).

7. Sumpf, B. et al., Proc. SPIE 6133, 613330D (2006).

8. Amzajerdian, F. et al., Sixth Annual NASA Earth Science Technology

Conference, College Park, Maryland, June 27-29 (2006).

9. F. Brunner, F. et al., Opt .Lett. 25, 1119 (2000).

10.Hu, M. H. et al., J. Lightwave Techno. 23,573 (2005).

11.Glebov, L.B., Photon. Spectra, January (2005).

12.Mustafa, F.H. , "Spectral Studies of Optical Injection of Nd:YAG laser by BLD", M.Sc. Thesis (2006).

13.Singh, J., Semiconductor Optoelectronics, McGraw-Hill, Inc, Univ.of Michigan, New York, USA, 1995.

14.Tomm, J.W. , Proceedings of the Symposium on Photonics Technologies for 7th Framework Program Wroclaw 12-14 October, Poland, (2006).

15.Poprawe, R., and Schulz, W., RIKEN Review 50,3 (2003).

16.Stephens, E.F., Mater. Res. Soc. Symp. Proc. 883, FF3.2.1 (2005)

17.Xi. E.F. et al., Jpn. J. Appl. Phys. 44, 7260 (2005).

18.Laikhtman, B., Gourevitch, A., Donetsky, D., Westerfeld, D., and Belenky, G., J. Appl. Phys. 95, 3880 (2004). 